\title{
Statistically Syndioselective Coordination (co)Polymerization of 4-Methyltiostyrene
}

\author{
Zichuan Wang ${ }^{1,2}$, Dongtao $\mathrm{Liu}^{1}$, , Dongmei Cui ${ }^{1} *$ \\ ${ }^{1}$ State Key Laboratory of Polymer Physics and Chemistry, Changchun Institute of Applied \\ Chemistry, Chinese Academy of Sciences, Changchun 130022, China \\ ${ }^{2}$ Graduate School of the Chinese Academy of Sciences, Beijing 100039, China \\ *Corresponding author. E-mail: dmcui@ ciac.ac.cn. \\ Tel: +86-431-85262773. Fax: +86-431-85262774.
}

Table S1. Copolymerization of MTS and styrene with different number-averaged sequence lengths

\begin{tabular}{ccccccc}
\hline entry & $\begin{array}{c}\mathrm{f}_{\mathrm{MTS}} \\
(\mathrm{mol} \mathrm{\% )}\end{array}$ & $\overline{\mathrm{n}}_{\mathrm{St}}$ & $\overline{\mathrm{n}}_{\mathrm{MTS}}$ & $\begin{array}{c}T_{\mathrm{g}} \\
\left({ }^{\circ} \mathrm{C}\right)\end{array}$ & $\begin{array}{c}T_{\mathrm{m}} \\
\left({ }^{\circ} \mathrm{C}\right)\end{array}$ & $\begin{array}{c}\Delta H_{\mathrm{f}} \\
(\mathrm{J} / \mathrm{g})\end{array}$ \\
\hline 1 & 0 & $\infty$ & - & 99 & 269 & -22.38 \\
2 & 9.6 & 8.22 & - & 101 & 228 & -12.64 \\
3 & 11.4 & 6.97 & - & 101 & 221 & -11.58 \\
4 & 12.4 & 6.42 & - & 100 & 217 & -8.52 \\
5 & 13.4 & 5.98 & - & 100 & 213 & -1.05 \\
6 & 13.9 & 5.75 & - & 100 & - & - \\
7 & 88.3 & - & 8.11 & 104 & - & - \\
8 & 90.0 & - & 8.48 & 105 & 223 & -0.32 \\
9 & 90.3 & - & 10.18 & 107 & 230 & -3.27 \\
10 & 100 & - & $\infty$ & 103 & 259 & -20.35 \\
\hline
\end{tabular}


Table S2. Polymerization of MTS and styrene ${ }^{a}$

\begin{tabular}{cccccccc}
\hline entry & $\begin{array}{c}\text { MeSPh content } \\
(\mathrm{mmol})\end{array}$ & $\begin{array}{c}\mathrm{f}_{\mathrm{MTS}}{ }^{b} \\
(\mathrm{~mol} \%)\end{array}$ & $\begin{array}{c}\text { time } \\
(\mathrm{h})\end{array}$ & $\begin{array}{c}\text { Yield } \\
(\%)\end{array}$ & $\begin{array}{c}\mathrm{F}_{\mathrm{MTS}}{ }^{c} \\
(\mathrm{~mol} \%)\end{array}$ & $\begin{array}{c}M_{\mathrm{n}}{ }^{d} \\
\left(\times 10^{4}\right)\end{array}$ & $\mathrm{PDI}^{d}$ \\
\hline 1 & 0 & 0 & $10 \mathrm{~min}$ & 99 & 0 & - & - \\
\hline 2 & 2 & 0 & $10 \mathrm{~min}$ & 58 & 21 & - & - \\
3 & 0 & 40 & 8 & 97 & 38 & 19.1 & 1.4 \\
4 & 2 & 40 & 8 & 64 & - & 12.6 & 2.2 \\
5 & 0 & 80 & 8 & 94 & 73 & 16.3 & 1.9 \\
6 & 2 & 80 & 8 & 30 & - & 11.2 & 2.2 \\
\hline 7 & 0 & 40 & 1 & $<5$ & 46 & - & - \\
8 & 2 & 40 & 5 & $<5$ & 41 & - & - \\
\hline 9 & 0 & 80 & 1 & $<5$ & 80 & - & - \\
10 & 2 & 80 & 5 & $<5$ & 77 & - & - \\
\hline
\end{tabular}

${ }^{a}$ General polymerization conditions: catalyst $\mathrm{Y}(10 \mu \mathrm{mol}),[\mathrm{Y}] /\left[\mathrm{Ph}_{3} \mathrm{C}\right]\left[\mathrm{B}\left(\mathrm{C}_{6} \mathrm{~F}_{5}\right)_{4}\right] /\left[\mathrm{Al}^{\mathrm{i}} \mathrm{Bu}_{3}\right]=1 / 1 / 10$ $(\mathrm{mol} / \mathrm{mol} / \mathrm{mol})$, toluene $(5 \mathrm{~mL}),[\mathrm{MTS}+\mathrm{St}] /[\mathrm{Y}]=500, T_{\mathrm{p}}=25^{\circ} \mathrm{C}$, unless otherwise noted. Data of odd number entries come from Table 1 and Table 3. ${ }^{b}$ Molar fraction of MTS in feed. ${ }^{c}$ Molar fraction of MTS in copolymer. ${ }^{d}$ Determined by GPC in THF at $40^{\circ} \mathrm{C}$ against polystyrene standard.

Annotation: In the copolymerization system, the competitive coordination between the polar methylthio group and the $\mathrm{C}=\mathrm{C}$ double-bond to the active metal center significantly decreased the homopolymerization activity of MTS as compared to that of St. To identify further the interaction between the methylthio group and yttrium center, we added a certain amount of MeSPh ([MeSPh]/[YY]=200) in the polymerization of St and copolymerization of St and MST. As results, the activities of both homo- and copolymerizations were obviously lower than the systems without thioanisole (Table S2, entries 1-6). This was understandable that MeSPh didn't participate the polymerizations just occupied the coordination sites.

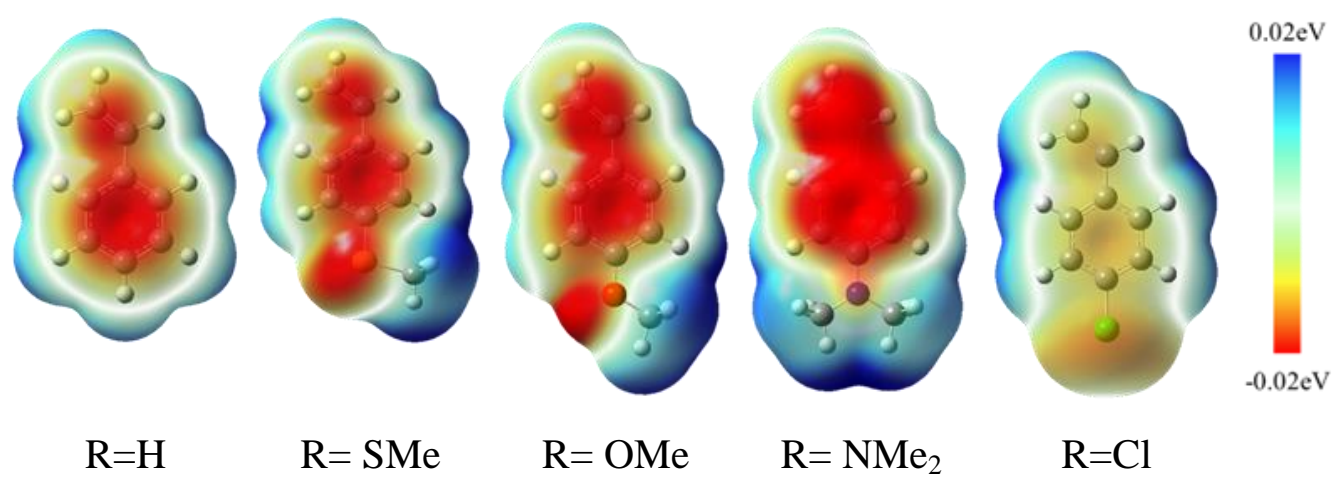

Figure S1. Electrostatic potential surface at isoval=0.0004, mapped from Total SCF Density 


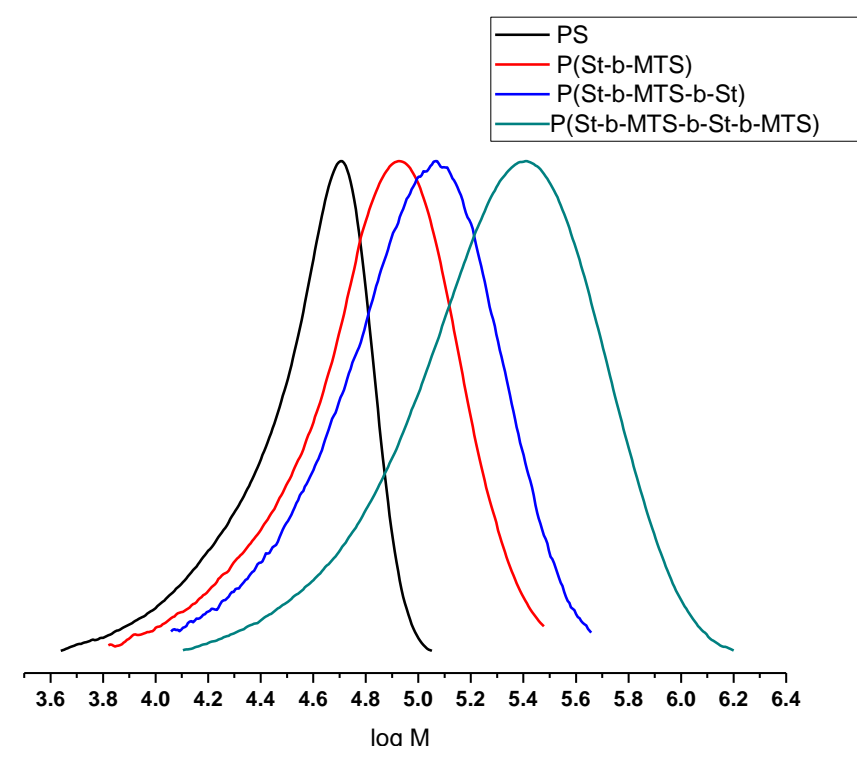

Figure S2 GPC curves of block copolymer in Table 3 (only the magnitude being uniformed)
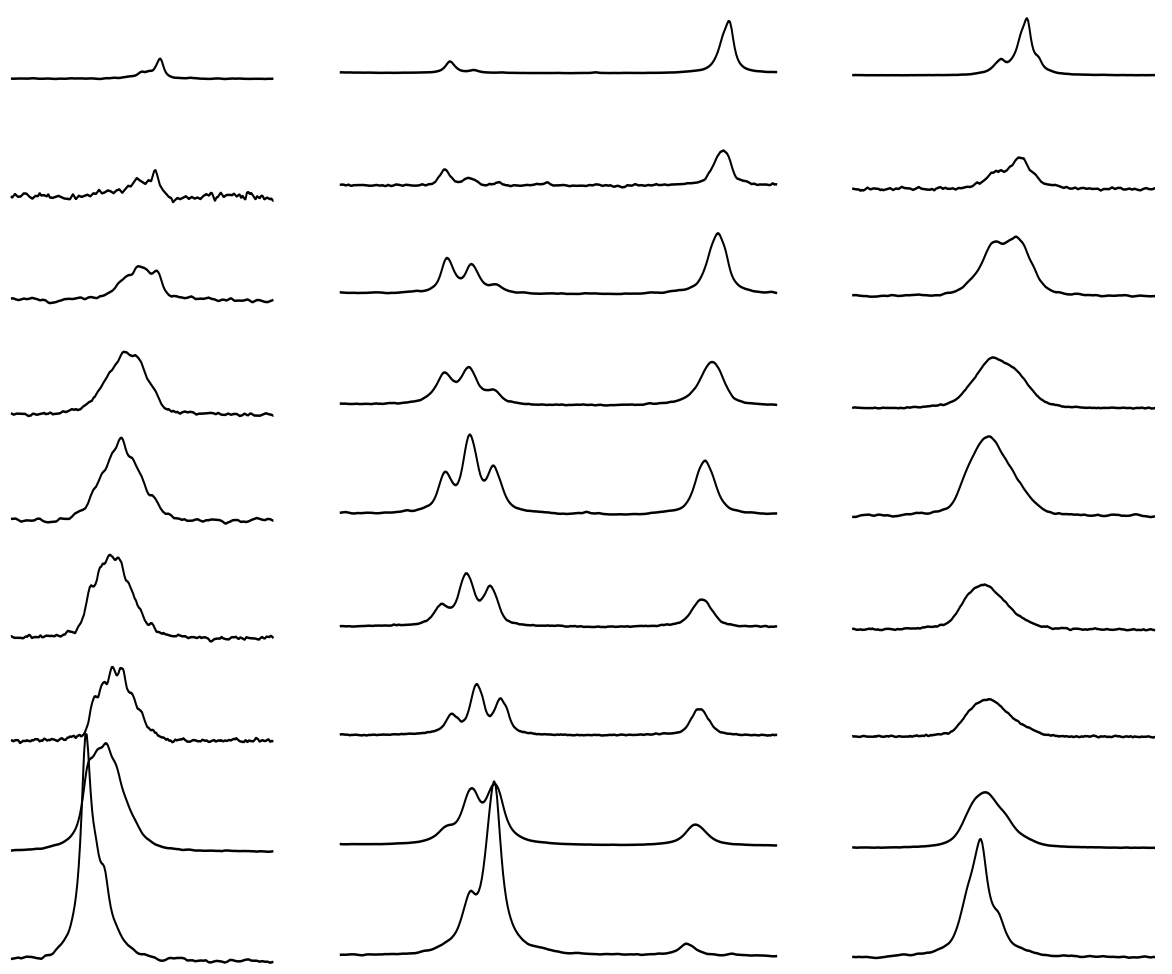

$1.3521 .348 \quad 1.344$
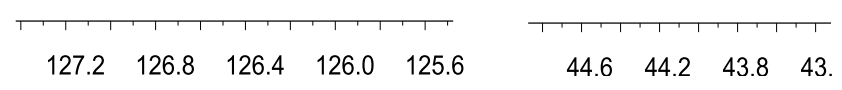

Figure S3 ${ }^{13} \mathrm{C}$-NMR spectra of the copolymers with different monomer feed ratios, $\mathrm{CDCl}_{3}$ as solvent. 


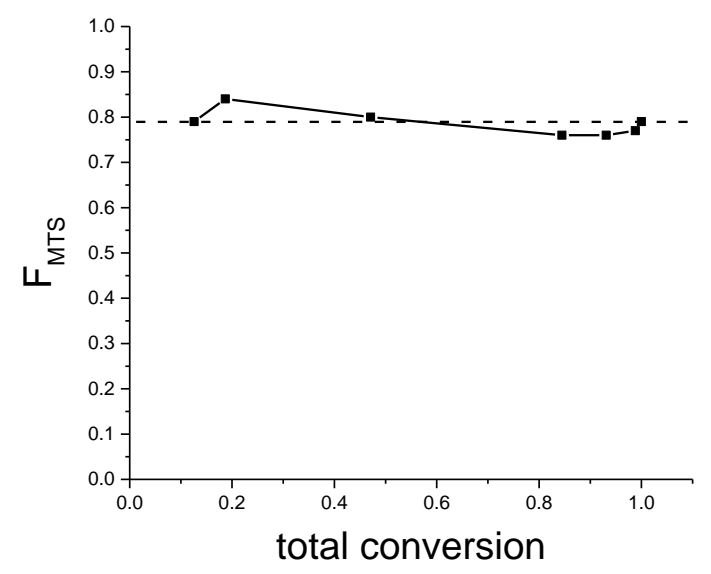

Figure S4. Molar content of MTS in the copolymerization of MTS and St.

Annotation: We tracked the variation of $\mathrm{F}_{\mathrm{MTS}}$ in a copolymerization of MTS and St $\left(\mathrm{f}_{\mathrm{MTS}}=0.8\right)$ and found MST consumed indeed faster as it should do (higher reaction ratio) when MTS conversions were lower than $50 \%$, since methylthio groups coordinate to the yttrium center and make MTS more easily to attach it. However in the late period of copolymerization, the methylthio groups surrounded the active metal centers mainly came from the copolymers rather than MTS, leaving less chance for MTS not only because concentration of MTS decreased. Therefore in the late stage of copolymerization $\mathrm{F}_{\mathrm{MTS}}$ dropped slightly as compared to that in the initial stage. Besides, we add a certain amount of thioanisole to imitate the environment of late period (Table S2, entries 8,10) and terminated at the conversion less than 5\%. Compared with the non-thioanisole copolymerizations (Table S2, entries 7, 9), both of them exhibited lower $\mathrm{F}_{\mathrm{MTS}}$, indicating that higher $-\mathrm{SMe} / \mathrm{C}=\mathrm{C}$ ratio leads to lower $\mathrm{F}_{\mathrm{MTS}}$. Nevertheless, it should be pointed out that $\mathrm{F}_{\mathrm{MTS}}$ didn't deviate much from $\mathrm{f}_{\mathrm{MTS}}$ during the polymerization.

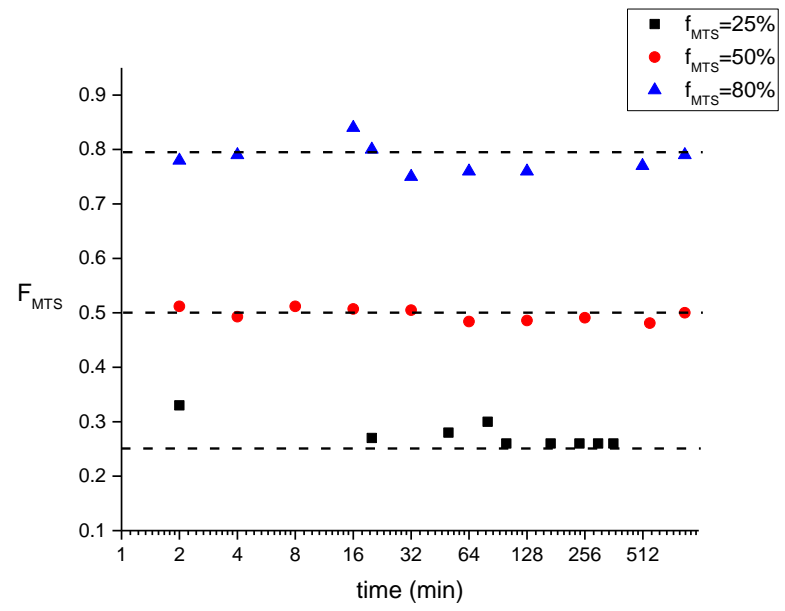

Figure S5. MTS fraction in copolymer via polymerization process 


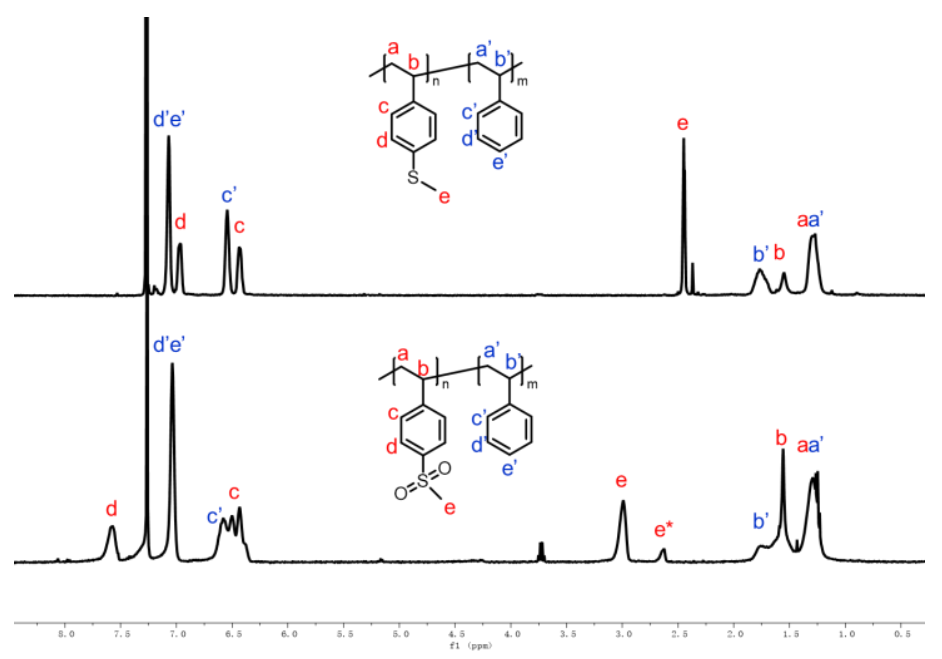

Figure S6. ${ }^{1} \mathrm{H}$ NMR spectra of P(St-co-MTS) and its oxide (by 1 equiv. 3-Chloroperbenzoic acid). Peak of $\mathrm{e}^{*}$ was attributed to the protons from sulphoxide ${ }^{1}$.

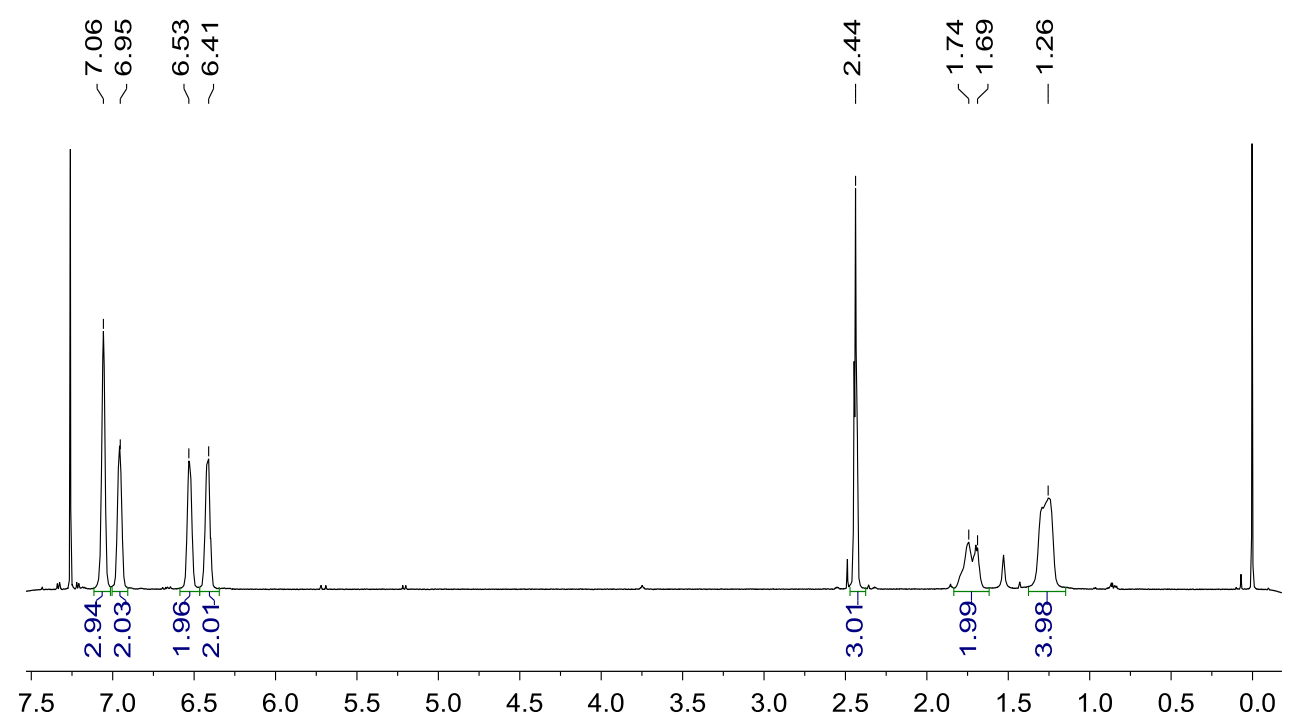

Figure S7. ${ }^{1} \mathrm{H}$ NMR spectrum of $\mathrm{P}(\mathrm{St}-\mathrm{co}-\mathrm{MTS})$ from Table 2, entry $5, \mathrm{CDCl}_{3}$ as solvent.

${ }^{1}$ Yu, B.; Liu, A.; He, L.; Li, B.; Diao, Z.; Li, Y. Green Chem. 2012, 14 (4), 957-962. 

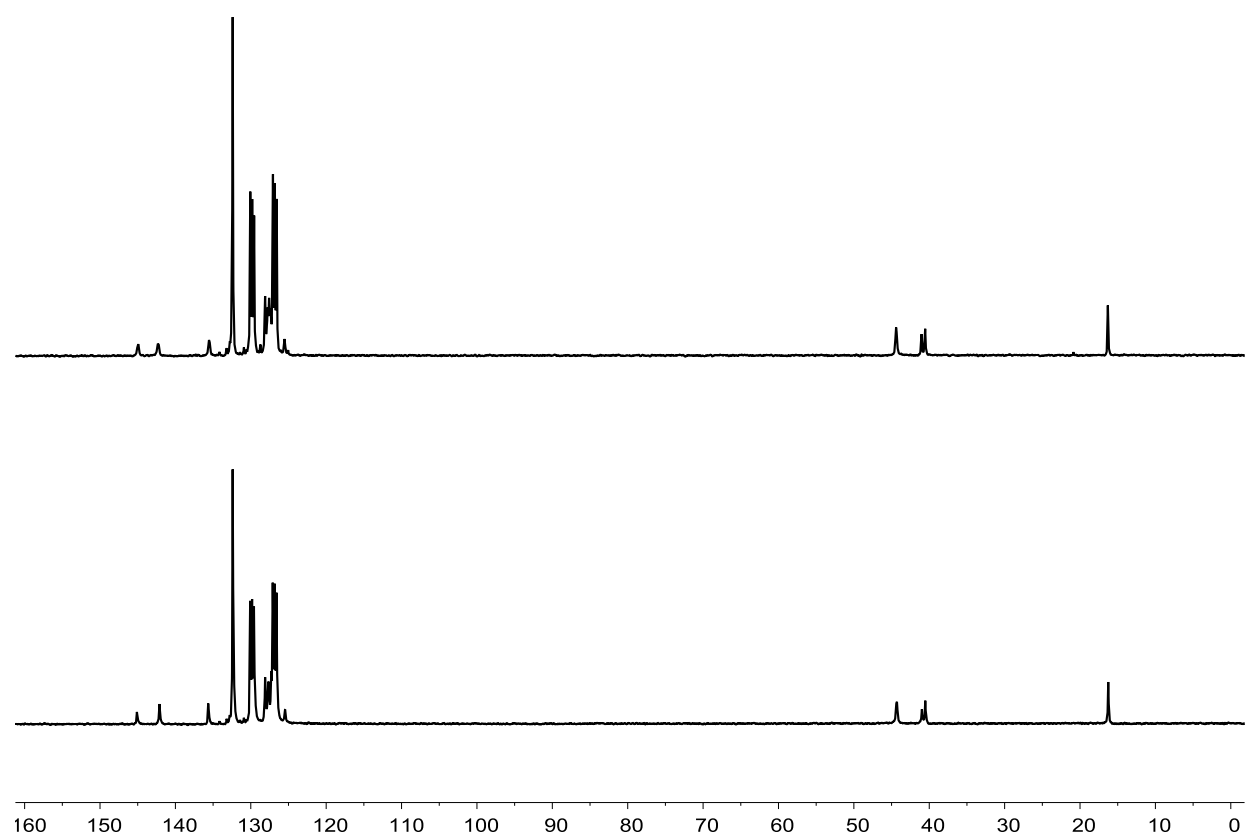

Figure S8. ${ }^{13} \mathrm{C}$ NMR spectra without clipping (Figure 3)

\section{Calculation for triads with the $1^{\text {st }}$ Markov statcistics.}

Probabilities for forming dyads:

Where 1-MTS, 2-St

$$
\begin{gathered}
p_{11}=\frac{R_{11}}{R_{11}+R_{12}}=\frac{r_{1}}{r_{1}+\left(\left[M_{2}\right] /\left[M_{1}\right]\right)} \\
p_{12}=1-p_{11} \\
p_{21}=\frac{R_{21}}{R_{21}+R_{22}}=\frac{1}{r_{2}\left(\left[M_{2}\right] /\left[M_{1}\right]\right)+1} \\
p_{22}=1-p_{21}
\end{gathered}
$$

By $1^{\text {st }}$-Markov statistics:

$$
\begin{gathered}
p_{\mathrm{S}}^{1}+p_{M}^{1}=1 \\
p_{\mathrm{S}}^{1}=p_{\mathrm{S}}^{1} p_{22}+\left(1-p_{\mathrm{S}}^{1}\right) p_{12}
\end{gathered}
$$

Probabilities for forming triads:

$$
\begin{aligned}
p_{S S S}= & p_{S}^{1} p_{22} p_{22}=\left[\left(1-f_{1}\right) p_{22}+f_{1} p_{12}\right] p_{22} p_{22} \\
p_{S S M} & =\left[\left(1-f_{1}\right) p_{22}+f_{1} p_{12}\right] p_{22} p_{21} \\
p_{M S S} & =\left[\left(1-f_{1}\right) p_{21}+f_{1} p_{11}\right] p_{12} p_{22} \\
p_{M S M} & =\left[\left(1-f_{1}\right) p_{21}+f_{1} p_{11}\right] p_{12} p_{21}
\end{aligned}
$$


Noting that $\left[\mathrm{M}_{2}\right] /\left[\mathrm{M}_{1}\right]$ didn't change a lot during the polymerization (Figure S5). 